\title{
El ascenso de la India: de colonia al umbral de gran potencia
}

\author{
Javier Alcalde Cardoza*
}

\begin{abstract}
RESUMEN
La India inició en 1947 procesos simultáneos de construcción de un estado-nación moderno y de posicionamiento internacional. Los liderazgos de Nehru e Indira Gandhi superaron consecutivamente grandes desafíos en la construcción de un Estado laico y democrático, el avance económico y el manejo de su ambiente externo. El fin de la Guerra Fría planteó a Delhi radicales cambios en sus políticas económica y exterior, los cuales enfrentó con éxito, liberalizando parcialmente su economía y acercándose a EE.UU. Estos cambios la han dejado a las puertas del estatus de gran potencia. Al mismo tiempo, se han robustecido fuerzas internas que empujan a la conformación de un Estado hindú.
\end{abstract}

Palabras clave: India, política exterior india, Nehru, Indira Gandhi, liderazgo, gran potencia, desarrollo económico, bomba atómica, Estados Unidos, nacionalismo hindú.

\section{The Ascent of India: From Colony to the Threshold of a Great Power}

\section{Abstract}

India began in 1947 simultaneous processes of state-building and international positioning. Under the leadership of Nehru and Indira Gandhi, consecutively, she was able to overcome great obstacles in the way of achieving a secular and democratic state, progress economically, and manage her external environment. The end of the Cold War confronted Delhi with the need to make radical adjustments in her economic and foreign policies. India partially liberalized her economy and came closer to the U.S. These changes have left India at the doors of Great Power status. At the same time, internal forces are striving to make of India a Hindu nation.

Keywords: India, Indian foreign policy, Nehru, Indira Gandhi, Leadership, Great Power, Economic development, Atomic Bomb, United States, Hindu nationalism.

\footnotetext{
* Internacionalista, Ph.D. en Asuntos Internacionales, profesor asociado en el Departamento de Ciencias Sociales, Pontificia Universidad Católica del Perú. Correo electrónico: jalcalde@pucp.edu.pe
} 


\section{Introducción}

La India, una de las grandes civilizaciones del mundo, consiguió a mediados del siglo XX adoptar la forma de un Estado moderno. Desde su creación, en 1947, prevaleció una imagen externa de la India como un Estado pobre y «subdesarrollado», internamente dividido por conflictos étnicos y religiosos y por ello con una limitada capacidad para influir sobre el orden internacional.

Se trata en realidad del Estado más heterogéneo del planeta, donde más de mil doscientos millones de personas hablan quince lenguas y mil seiscientos dialectos regionales, profesan una fe mayoritaria, el hinduismo ( $82 \%$ de la población), pero también el Islam (12\%), el cristianismo, el sikhismo y otras religiones. Dentro del hinduismo, pertenecen a castas y subcastas que los diferencian y, especialmente en el ámbito rural, condicionan todavía sus ocupaciones y tipos de vida.

Sin embargo, hoy en día, por el crecimiento económico, capacidad tecnológica y estatus nuclear que ha logrado en las últimas décadas, muchos consideran que India es una potencia emergente a las puertas de convertirse en una gran potencia. Aunque subsiste la opinión de quienes sostienen que las contradicciones y los problemas estructurales de este Estado hacen que su avance económico y su poder sean poco consistentes, pues ambos se hallan socavados por la corrupción pública, una pobre infraestructura, una creciente desigualdad y pocas mejoras materiales para las mayorías.

En este sentido, los internacionalistas Buzan y Waever afirman que después del fin de la Guerra Fría, India "tocaba fuertemente la puerta» del círculo de las grandes potencias pero carecía de las capacidades necesarias y el reconocimiento formal de los titulares del mismo. Adicionalmente, consideran que estos Estados no veían en India el potencial para convertirse en una gran potencia en el corto o mediano plazo (Buzan y Waever, 2003, p. 36). Estas apreciaciones fueron formuladas antes del acuerdo nuclear de India con EE.UU. (2005).

La evolución de India representa un caso poco común en la historia contemporánea porque sus gobernantes desde el inicio intentaron impulsar simultáneamente los procesos de formación de un Estado moderno así como una ambiciosa estrategia de posicionamiento internacional.

En tanto que Gandhi fue el gestor de la independencia de la India, la visión de Nehru fue la que determinó la forma del Estado indio como su lugar en el concierto internacional. Y los gobiernos de Nehru y de su hija, Indira, se encargaron de plasmar, en buena medida, esta visión. 
Nehru e Indira (y tal vez también Manmohan Singh, el conductor de la liberalización económica) encarnan, a nuestro parecer, un ejemplo histórico de lo que Renouvin y Duroselle consideran la capacidad de los líderes políticos de modificar, a través de una acción sostenida, las estructuras básicas de una nación (Renouvin y Duroselle, 1967, pp. 320-329) ${ }^{1}$.

Los grandes procesos de cambio ciertamente no han concluido en la India, estando en ascenso, por ejemplo, las fuerzas de un nacionalismo hinduista, pero la dinámica y varias de las direcciones impuestas por Nehru e Indira están en la base de la nueva fortaleza y estatus logrados por esta potencia.

La India inició sus esfuerzos por obtener la independencia con la creación del Partido del Congreso, en 1885, en gran medida como reacción a las nocivas políticas británicas de desindustralización y exportación de cereales en la colonia (Rosser y Rosser, 2004, pp. 462-465).

Gandhi dirigió la resistencia pacífica con eficaces resultados desde 1920 hasta 1934. En 1935 Londres concedió el autogobierno y una constitución a la India pero el movimiento hacia una independencia total se volvió incontenible después de la Segunda Guerra Mundial.

Nehru intentó llegar a un acuerdo con Jinnah, líder del órgano de la minoría islámica, la Liga Musulmana, para establecer un gobierno compartido en el futuro Estado, pero las negociaciones fracasaron a mediados de 1947. Londres decidió entonces que la independencia traería a la existencia dos Estados (uno de ellos, Pakistán, dividido en un territorio occidental y otro oriental). Tres cuartas partes del territorio quedaron para los hindúes y Nehru optó por conservar el nombre de India para su Estado, contra las objeciones de Jinnah.

La partición demandó la separación de comunidades, arreglos económicos e instituciones de administración y fuerza armada, pero sobre todo un cruento proceso de desplazamiento de grupos que deseaban residir en el Estado donde su religión era mayoritaria. En unos pocos meses, diez a doce millones de personas dejaron sus lugares de residencia; en medio de un colapso total del orden, un millón de personas murieron por enfrentamientos, masacres e inanición. La partición dejó heridas difíciles de curar en India y Pakistán.

\footnotetext{
1 Renouvin y Duroselle ponen el ejemplo de la transformación de México gracias a las acciones de líderes políticos desde Benito Juárez hasta Lázaro Cárdenas (1858-1940).
} 


\section{La dimensión política}

\section{Nehru y las grandes tareas de construcción de la India}

Con la independencia, el Partido del Congreso decidió adoptar un sistema democrático federal como la mejor fórmula para asegurar la tolerancia y el disfrute de iguales derechos para todos los indios, por encima de su particular religión, lengua o casta. Triunfó la visión de Nehru de un estado laico, sobre la visión de Sardar Patel, el viceprimer ministro, de un estado hindú 2 . En esos momentos, solo Japón en el Asia había adoptado efectivamente la democracia: al hacerlo contaba con las ventajas de un tamaño bastante menor que la India, una población homogénea y una unidad histórica.

La responsabilidad de dar forma al nuevo Estado recayó en Nehru (por el asesinato de Gandhi). A la cabeza del Estado, Nehru asumió el extraordinario reto de ejercer con moderación una autoridad que formalmente tenia pocos límites. En la práctica, desde la muerte de Sardar Patel, quien encabezaba el ala derecha del Partido, el liderazgo de Nehru no encontró mayores contrapesos. Nehru gano tres elecciones consecutivas, sin una mayoría absoluta pero enfrentando siempre a una oposición dividida, en 1952, 1957 y 1962.

Entre las grandes tareas prácticas que conlleva la formación de un estado moderno sobresalen la construcción del aparato institucional del mismo así como la promoción de una identidad común y la cohesión entre los individuos que constituyen la nación. También es muy importante la consecución de una adecuada distribución de recursos entre los distintos sectores de la población ${ }^{3}$.

Nehru, el arquitecto de la India, acometió las tareas de construir el estado y dotar de recursos básicos a una población en la que grandes sectores se hallaban en una pobreza absoluta. Después del gobierno de Nehru, su hija, Indira, profundizó, a veces de manera controversial, las colosales tareas que conllevaba la distribución.

Se puede afirmar que tanto Nehru como Indira consiguieron en sus respectivos gobiernos movilizar a la población hacia el abordaje de fundamentales problemas comunes y dieron en este empeño a los indios suficientes motivos para fortalecer su orgullo como nación.

Sin embargo, se puede decir también que estos dos excepcionales estadistas no avanzaron mucho más en la construcción de la nación. Nehru creía profundamente en

\footnotetext{
2 Fue precisamente un seguidor de una organización nacionalista hindú de carácter extremista quien asesinó a Gandhi en 1948.

3 Una distribución que resulte adecuada a las concepciones y designios de los estadistas acerca del Estado en cuestión. Sobre las teorías del desarrollo político, véase C. Dodd, Political Development (1972) y D. Rustow, $A$ World of Nations (1967).
} 
la unidad de la diversidad y pensó que con una mínima interferencia de un Estado laico, los diferentes elementos culturales de la India encontrarían por sí solos la complementariedad.

En la práctica, la extraordinaria diversidad de la población planteó a ambos gobernantes los agudos problemas de una nación con distintas lenguas, castas y religiones. Los problemas acabaron por rebasar, en distintos momentos, la capacidad de los dos líderes así como la del Partido del Congreso y abrieron el camino para el fortalecimiento del nacionalismo hindú, el cual se alejaba de las premisas del estado laico y se volvió, en la década de 1980, un nuevo gran actor en el desarrollo político de la India.

En efecto, después de tres décadas de logros en la construcción del Estado y de notables avances en el terreno de la distribución, a cargo de Nehru, Indira y el Partido del Congreso, cobró fuerza a partir de la década de 1980, un poderoso y a veces violento movimiento político-religioso orientado, en principio, a la construcción de una nación hindú.

El Partido del Congreso, que hasta entonces solo había perdido una elección, en 1977, dejó de ser el partido dominante. El nacionalismo hindú vino también a contribuir con nuevas energías a definir un trascendental proceso de cambio en la conducción política de la economía dando una mayor libertad a las fuerzas del mercado.

$\mathrm{Al}$ asumir como primer ministro, en agosto de 1947, la primera tarea en la construcción práctica del Estado que abordó Nehru fue la incorporación de los cientos de principados que formaban parte de la India colonial a la estructura federal del nuevo Estado. Este fue un proceso laborioso que se realizó hasta 1949 de manera pacífica, con dos excepciones.

En octubre 1947, en uno de estos principados, Cachemira, donde un príncipe hindú gobernaba a súbditos mayoritariamente musulmanes, se produjo una rebelión instigada por Pakistán. El gobernante pidió ayuda a Delhi y las tropas indias se enfrentaron a las fuerzas pakistaníes. El conflicto escaló hasta convertirse en una guerra, que fue la primera entre India y Pakistán, escasos meses después de la creación de ambos Estados.

La guerra fue detenida por un cese del fuego logrado a través de mediación de la ONU entre 1948 y 1949, que dejó a India en posesión de dos tercios del territorio de Cachemira. Delhi e Islamabad aceptaron que el destino de Cachemira fuera resuelto por un plebiscito pero no acordaron la mecánica. Posteriormente, la India dejó de apoyar el plebiscito, movida por la determinación de evitar la posibilidad de mayores pérdidas territoriales por las preferencias de poblaciones musulmanas ${ }^{4}$.

4 Muchos vieron la creación de Pakistán como un cercenamiento del territorio de la India. 
La partición de Cachemira intensificó la animadversión entre India y Pakistán, que hasta la fecha han protagonizado otras tres guerras (en 1965, 1971 y 1999).

Por el contrario, en el caso del principado musulmán de Hyderabad, con una mayoría de población hindú, el príncipe resistió la incorporación a la India hasta que el ejército indio ocupó Hyderabad, en 1948, en lo que fue considerado por Delhi como una intervención policial.

La configuración federal de la India se vio pronto amenazada por la emergencia de movimientos étnicos que planteaban la reorganización de los estados en aras de asegurar la integración de sus respectivas comunidades. La respuesta positiva del gobierno a estas demandas, en 1956, efectuando cambios en la configuración de los estados a base de las lenguas predominantes, contribuyó a aumentar la agitación étnica. En algunos casos revivieron los temores de la partición.

Una segunda tarea en la construcción del Estado requirió la creación de una administración pública y un ejército nacionales. Nehru sancionó la continuidad de los indios que trabajaban en la administración y el ejército de la India británica en las nuevas instituciones nacionales; y optó así por aprovechar su valiosa experiencia y evitar incurrir en los esfuerzos y riesgos de formar nuevos cuadros. En esta misma línea, Nehru decidió mantener el inglés como segunda lengua oficial, al lado del hindi, lo cual tendría una gran importancia para el desarrollo tecnológico del país.

El Partido del Congreso junto con la burocracia estatal, el ejército y la policía, fueron elementos decisivos para consolidar la centralización de la India.

En el campo de la distribución, una tercera tarea fundacional — para Nehru, la más importante de cara al futuro de la India - fue la prosecución del desarrollo económico y la introducción de reformas sociales con miras a mejorar el bienestar de las masas y lograr el designio estratégico de una autosuficiencia nacional.

En 1950, la mitad de la población india vivía en la pobreza absoluta. Para afrontar esta situación, Nehru no propuso un programa de redistribución de la riqueza sino un esquema de economía mixta en la que el Estado tendría considerables poderes para encauzar el crecimiento económico atendiendo a fines políticos y sociales.

La herramienta fundamental del Estado fue una planificación de carácter indicativo, a través de la cual ejercía un papel de guía de la economía. El modelo que Nehru tenía en mente, aunque con reparos por su falta de democracia, era la URSS, la cual en menos de dos décadas había podido transformarse en una economía industrial.

En contraste con el consenso existente respecto a la democracia, la prosecución del socialismo —entendido como la mejora de la situación de los pobres y la reducción 
de las desigualdades - fue activamente contestada por el ala derecha del partido y Nehru solo pudo desarrollar sus políticas sociales después de la repentina muerte del líder conservador, Patel, en 1950, que le permitió controlar el partido.

En el campo se realizó una reforma agraria y se lanzó en 1952 los primeros planes de desarrollo de la comunidad y desarrollo rural, que fueron pioneros en el mundo. De manera más amplia, el desarrollo industrial se impulsó a base de una forma propia de sustitución de importaciones (Little, 1982, p. 51), que tuvo como protagonistas al Estado y al empresariado nacional. En este caso, en gran medida como consecuencia del trauma que había producido la manipulación británica de la economía, se adoptó el proteccionismo. En 1954 el Partido del Congreso se fijó formalmente la meta de establecer una sociedad de corte socialista (Wolpert, 1997, p. 362).

Nehru fue un apasionado promotor de la educación. Además de establecer la instrucción primaria universal y de extender la educación al campo, alentó la educación superior, especialmente en los terrenos de la medicina, la administración y la tecnología. Emuló la política soviética de establecer centros de investigación en ciencias físicas y escuelas de ingeniería de primer nivel (los cuales, junto con el uso del inglés, serian piezas clave para los avances materiales de India).

La economía india bajo el gobierno de Nehru, entre 1950 y 1965, creció a un 4\% anual, lo cual estaba por debajo de las tasas de expansión de «milagros» económicos como los de Alemania y Japón y de los «tigres» asiáticos pero por delante de las de Estados Unidos y Gran Bretańa. El desarrollo de la India ocurrió sin programas de reconstrucción ni auspicios externos y sacudiendo de una inercia milenaria a estructuras sociales y económicas de dimensiones colosales.

\section{Los liderazgos de Nehru e Indira}

Nehru ejerció con notable moderación el considerable poder que le daba la Constitución así como la ventajosa situación política de la que disfrutaba el Partido del Congreso entre el electorado; este fue uno de los principales rasgos de su grandeza como líder.

Sin embargo, durante su gobierno tuvo lugar un hecho que fue clave para desarrollar una tendencia que vendría a despertar opiniones encontradas sobre su legado: el ingreso de su hija a la dirección del gobierno, el cual llevaría ulteriormente a la creación de una «dinastía».

5 Esto habría sido facilitado también por el bajo nivel educativo del electorado, propenso al culto del «gran líder». 
En 1952, Indira se había convertido en la más cercana colaboradora y consejera de su padre. Siete años más tarde, en 1959, consiguió ser elegida presidenta del Partido del Congreso. No quedó clara la posición de Nehru frente este suceso. Dada las profundas convicciones democráticas de Nehru y el hecho de que después de la elección de Indira no ofreciera a ella un cargo en el gabinete ministerial, podría pensarse que no estuvo de acuerdo con lo sucedido.

Sin embargo, un célebre periodista indio, Durga Das, presenta una diferente historia, aseverando que desde 1957 se podía percibir un designio de Nehru de convertir a Indira en su sucesora y que su elección en el partido fue un arreglo sospechoso de último momento (Das, 2015, pp. 368-372 y 400-401).

Nehru se resistió siempre a hablar de su sucesor. A su muerte, en 1964, un grupo de líderes que Nehru había posicionado en el partido, conocido como el Sindicato, colocó a Shastri en el premierato, por la facilidad que esperaba tener para trabajar con él.

Shastri falleció en 1965, al finalizar una segunda guerra con Pakistán; el Sindicato escogió esta vez a Indira como primera ministra (en enero 1966), por encima de Morarji Desai, un político mucho más experimentado, prestigiado y con peso propio. La selección de Indira, que era una ministra junior en el gabinete, se habría debido en alguna medida a la creencia del Sindicato de que la hija de Nehru sería muy débil para resistir sus influencias. En los seis años siguientes, hasta 1971, sin embargo, Indira demostraría una insospechada fortaleza y habilidad, no solo para imponerse sobre el Sindicato sino también sobre Desai y lograr el control del partido.

La mala situación económica después de la guerra con Pakistán (1965) (que veremos en la sección 6) y dos años consecutivos de sequías hicieron que el gobierno de Indira, a instancias de EE.UU., devaluara la rupia en 1966 y entrara en un breve proceso de liberalización de la economía, apoyado por ayuda económica y alimentaria de EE.UU.

Las elecciones del año siguiente, 1967, significaron el cierre de la era de oro del Partido del Congreso, al mantener estrechamente una mayoría en el plano nacional pero perdiendo en varios estados importantes. La declinación del partido fue vista como una señal amenazante para el futuro del Estado. Como primera ministra, Indira decidió entonces, estratégicamente, inclinarse a la izquierda, siguiendo la tendencia que percibía dominante en el sistema político. Realizó una serie de nacionalizaciones y desarrolló una creciente regulación del sector privado.

A raíz del resultado de las elecciones de 1967 se intensificó también la lucha por el control del partido. En la elección de un nuevo presidente de la República en 
el Parlamento, en 1969, Indira respaldó a un candidato propio, Giri, contra el Sindicato, y consiguió imponerse. También destituyó a Desai del cargo de ministro de Finanzas. Desai se unió al Sindicato y juntos consiguieron expulsar a Indira del partido.

La crisis culminó cuando Indira decidió separarse del partido con sus seguidores y formó el Partido del Congreso (R), con un mayor número de parlamentarios que la otra facción, a la que se denominó Congreso $(\mathrm{O})$. Se produjo así un cisma en la principal agrupación política del país, el cual favorecería la gestión de Indira.

En el Cuarto Plan Quinquenal, que Indira lanzó en 1969 se reflejó claramente una posición adversa a la dependencia alimentaria del país. El plan consolidó un mayor control del Estado sobre la economía y buscó avanzar hacia la satisfacción de las necesidades básicas de las masas, al impulsar el desarrollo rural así como un gran aumento de la productividad agrícola con miras a la autosuficiencia ${ }^{6}$.

En la campaña para las elecciones de 1971, Indira lanzó como elemento central un programa de erradicación de la pobreza, políticamente encaminado a ganar el apoyo de los pobres de la ciudad y el campo. Una orientación socialista caracterizaría a su gobierno hasta 1975 .

En 1975 el Poder Judicial determinó la anulación de la elección de Indira al Parlamento en 1971, por malas prácticas electorales y le prohibió ejercer cargos políticos por seis años. Se produjeron grandes manifestaciones para pedir la renuncia de Indira. Esta hizo declarar un estado de emergencia, sustentado en la necesidad de restablecer el orden, y condujo luego el gobierno por decreto. Aplicó drásticas medidas no solo para restaurar el orden, sino también para debilitar a sus opositores y mejorar la situación de la economía, que era otra de las causas del descontento popular.

Durante la emergencia, el hijo menor de Indira, Sanjay, quien había entrado al partido en 1971 sin ninguna experiencia, ejerció un enorme poder, utilizó métodos autoritarios y aun violentos y adquirió un aura de heredero político de su madre que despertó reacciones adversas del público.

El estado de emergencia, el papel de Sanjay y algunas políticas impopulares del gobierno, como las de esterilizaciones forzosas y demolición de barrios pobres (dirigidas por Sanjay), contribuyeron a la derrota de Indira en las elecciones de 1977 y el triunfo del Partido Janata, que pudo gobernar hasta 1980.

\footnotetext{
6 Este proceso de incremento de la productividad de algunos cereales se denominó Revolución Verde a nivel internacional.
} 
En 1980 Sanjay sufrió un accidente fatal, al estrellarse en su avioneta particular. Rajiv, su hermano mayor, postuló a la curul que Sanjay dejó en la Cámara Baja del Parlamento (Lok Sabha) y fue elegido. En este momento trágico se hicieron patentes los designios dinásticos de Indira.

Rajiv era un piloto de Air India que no había mostrado ningún interés por la política pero fue lanzado por su madre al ruedo político y convertido en el nuevo heredero del poder. En los años siguientes se iniciará una glorificación de la dinastía en el partido y en el gobierno y, por otro lado, este mismo comportamiento dinástico se verá replicado en otros estados de la Unión, con los cargos de primer ministro y de líder del partido convertidos en patrimonios familiares (McLeod 2002, p. 161).

En el diseño del sexto plan quinquenal (1980-1985) a Indira le cupo un rol pionero en la liberalización de la economía, al introducir medidas para reducir el gasto público (Diro, 2010, p. 193). Por ello fue acusada de traicionar al socialismo.

En junio de 1984, la primera ministra decidió ordenar un asalto al Templo de Oro de los sikhs en Amritsar, donde se habían hecho fuertes extremistas sikhs que buscaban crear un Estado propio en el Punjab. Cuatro meses más tarde, en octubre, Indira murió asesinada por dos de sus guardaespaldas sikhs que quisieron vengar la profanación del Templo de Oro.

Podemos afirmar, con Flavoni, que en la era de Indira, la India de Nehru se convirtió en un país más moderno pero más agitado y dividido. Se habla así de dos eras, la de Nehru y la de Indira, que reflejarían las personalidades diferentes del padre y la hija pero también distintos contextos sociales y políticos.

La primera era habría estado caracterizada por la búsqueda del consenso y una relativa moderación de los intereses en competencia; en la segunda, los contrastes se intensificaron y el poder se personalizó. Se debilitó la centralización y ganaron poder las regiones.

Bajo Nehru, el Estado y el partido del Congreso operaban como factores de transformación y tenían una mayor capacidad para afrontar y resolver los problemas del gobierno. Con Indira, las presiones y problemas llegaron a un clímax y desnudaron los límites de las instituciones y de sus capacidades para responder a las demandas populares y a los conflictos políticos (Flavoni, 2003, p. 71)

Para apreciar la magnitud de los desafíos y dificultades que tuvo que superar Indira en su gobierno, recordemos que varios observadores pronosticaban que a la muerte de Nehru y la pérdida de su liderazgo seguiría la desintegración de la India.

7 Por ejemplo, Selig Harrison en 1960 y Neville Maxwell en 1966, según Chadda (2015, p. 242). 
Coincidentemente, después de la muerte de Nehru (1964) la situación externa vino también a complicarse para la India. Se dio una alianza de China con Pakistán (1963) y una segunda guerra de este con la India (1965). Debido a la guerra, la economía quedó en mala situación y empeoró aún más con dos años consecutivos de sequía (1965 y 1966). Estos problemas se sumaron a las pugnas que enfrentaba Indira en su propio partido, en el Parlamento y en su gabinete.

Nehru e Indira son las dos figuras políticas más importantes de la India independiente. Gobernaron por más de tres lustros cada uno y volvieron su liderazgo consustancial al Estado. A la muerte de Indira, como ante la muerte de su padre, se pensó en la posible desintegración de la India.

A partir de las reflexiones de Ramachandra Guha (2007, pp. 572-574) compararemos brevemente a estos dos gigantes políticos.

Nehru ideó a la India como Estado y sacó su proyecto adelante, particularmente en los planos del desarrollo económico y las relaciones internacionales. Echó las bases de la industria y la lucha contra la pobreza y creó una brillante imagen internacional para India, consiguió utilizar las credenciales de esta como civilización para impulsar las aspiraciones nacionales de potencia mayor, asentadas en el no alineamiento y el anticolonialismo.

Indira no tuvo una gran visión original como su padre pero supo mantenerla y hacerla avanzar en momentos adversos. Al considerarlo necesario, consiguió radicalizar con éxito la visión de Nehru en el desarrollo y las relaciones internacionales y fue superior a su padre como líder militar. Como Nehru, fue una líder que buscó representar los intereses de todos los indios, sin preferencias de clase, etnicidad o religión.

En lo que Nehru fue superior a su hija fue en el respeto de las normas y procedimientos de la democracia. Indira manejó a discreción el partido y el gobierno; de esta manera contribuyó a quebrar la prohibición del uso del Estado para fines privados y a fomentar la división política.

Nehru, por su parte, fue criticado por descuidar la defensa nacional, por desarrollar un excesivo moralismo en su política exterior y por no anticipar las intenciones de China y Pakistán hacia la India.

Podemos decir que Indira, como líder, se caracterizó por la dureza de su comportamiento político y por una escasa tolerancia hacia sus opositores, que la llevó a conseguir una centralización sin precedentes del poder en su gobierno.

Algunos autores, como Flavoni, consideran que Indira fue una líder que buscó una relación directa con el pueblo y que en su intento de cambiar las injusticias del 
sistema no vaciló en pasar por encima de rivales políticos y aun de instituciones (Flavoni, 2003, p. 79).

Otros autores la ven como uno de los líderes más fuertes del siglo XX. Su biógrafo, Inder Malhotra (1989), afirma que ningún otro líder de un gobierno democrático del siglo XX, excepto quizás De Gaulle, se identificó tan completamente con los destinos de su país (Flavoni, 2003, p. 70).

Nehru fue un líder de extraordinario carisma y visión que pudo poner a una India enorme y heterogénea en un camino de formación y preeminencia como Estado. Contó con la singular fortuna de tener un mentor como Gandhi que le confirió una gran autoridad para conducir el Partido del Congreso y luego desapareció, dejándolo solo en la dirección del mismo. Igualmente, su proyecto laico y socialista del Estado indio pudo prevalecer por la temprana ausencia de su rival en el partido, Patel. Del triunvirato que dominaba el partido — Gandhi, Nehru, Patel— en 1950 solo quedó Nehru.

Pero Nehru fue poseedor de un idealismo que en alguna medida limitó su uso de las herramientas políticas que hubieran podido combatir eficazmente las amenazas que planteaban a su proyecto nacional poderosas fuerzas internas.

Indira, en cambio, por su temperamento y experiencias políticas tempranas, pudo desarrollar la energía y habilidades que le permitieron enfrentarse exitosamente a estas fuerzas. Las enfrentó de una manera pragmática, sin dar siempre importancia a las formas democráticas, inclusive a la de la alternancia en el poder, y buscó asegurar con sus descendientes la continuidad del proyecto de Nehru.

La versatilidad de Indira con el propósito de permanecer en el poder y gobernar con eficacia puede percibirse primero en su inclinación a un reformismo de izquierda y luego hacia la liberalización de la economía. También, en la década de 1980, en su cortejo al ascendente nacionalismo hindú, con el objeto de capturarlo para seguir impulsando su proyecto nacional.

\section{Rajiv y la declinación del Partido del Congreso}

Inmediatamente después del asesinato de su madre, en noviembre 1984, Rajiv Gandhi fue nombrado primer ministro por el Partido del Congreso. En la campaña de las elecciones generales que se programaron, Rajiv, resultó ser un candidato muy popular por su energía, juventud y atractiva apariencia, así como por su condición de recién llegado a la política. Derrotó concluyentemente al BJP, representante del nacionalismo hindú, debido a que supo ganar el voto hindú, que su madre había estado cortejando recientemente, incorporando matices nacional-religiosos en su gestión (Flavoni, 2003, p. 180). 
Rajiv aparecía como el líder indicado para emprender la tarea de reformar la economía, rompió estructuras político-económicas que parecían haberse esclerosado. Al asumir el cargo de primer ministro denunció la corrupción, que era la mayor traba para el crecimiento. Más adelante, en su gestión económica, se encargó de debilitar el régimen de licencias, los controles a las importaciones y las restricciones para las inversiones conjuntas de indios y extranjeros.

Rajiv se preocupó por la modernización de las fuerzas armadas. También mostró un fuerte interés personal por acelerar el desarrollo de la industria informática, que consideraba crucial para el futuro del país, para lo cual promovió la innovación tecnológica y decretó la liberalización del sector. Ambas medidas fueron decisivas para el despegue informático de la década de 1990.

El primer ministro buscó adquirir la supercomputadora Cray X-MP-24 de EE.UU. pero Washington vetó la adquisición por temor a que fuera utilizada en el programa nuclear del gobierno. Entonces optó por crear un centro de investigación avanzada sobre computación en la ciudad de Pune (1988) que logró construir una supercomputadora de bajo costo en tres años (Rothermund, 2008, pp. 112-113).

Pero las reformas económicas que realizó Rajiv, quien se mantenía distante de las masas y tenía fama de tecnócrata, pronto fueron percibidas como sesgadas en favor de los ricos. Por otro lado, su gabinete era débil y muchos de los asesores eran amigos suyos del colegio, y formó así un entorno que se prestaba a suspicacias.

Surgieron varias protestas, especialmente de grupos campesinos en 1985 y 1986 y las reformas se detuvieron. Además, en 1986 estallaron graves conflictos entre hindúes y musulmanes relacionados con el templo de Ayodhya (como veremos más adelante).

El problema de la corrupción apareció con fuerza en el gobierno en enero de 1987, cuando uno de los ministros de Rajiv con especial fama de honradez, V.P. Singh ${ }^{8}$, salió de la cartera de Finanzas a consecuencia de los problemas que creó al investigar casos de corrupción en su sector. Singh tuvo que salir luego del ministerio de Defensa, al provocar un escándalo por la revelación del caso Bofors; poco después sería expulsado del partido.

El escándalo Bofors, de corrupción por una firma sueca a allegados de Rajiv en la venta de material militar, dañó al gobierno y a la imagen de limpieza del primer ministro. Provocó un enfrentamiento de Rajiv con el presidente de la República, G.Z. Singh, quien aparentemente buscaba destituirlo.

\footnotetext{
8 El apellido Singh es común a todos los que profesan la religión sikh pero también existe fuera de esta religión. V.P. Singh, por ejemplo, no es un sikh.
} 
Por su parte, V.P. Singh, después de su salida del Partido del Congreso, creó un movimiento contra la corrupción e ingresó al Parlamento. Organizó un nuevo partido, el Janata Dal y este triunfó en las elecciones generales de 1989 llevándolo al cargo de primer ministro.

El nuevo gobierno del Janata Dal experimentó dificultades y se fragmentó rápidamente. Rajiv ideó una maniobra que forzó a la convocatoria de elecciones en 19919. Entró luego en campaña pero, siguiendo la suerte trágica de su familia, fue asesinado en un atentado de un grupo tamil, allegado a los tamiles de Sri Lanka que habían sido combatidos por el ejército indio en la intervención en este país decretada durante el gobierno de Rajiv (1987).

Después del asesinato, la dirección del partido fue ofrecida a Sonia Gandhi, viuda de Rajiv (nacida italiana y nacionalizada india), pero ella prudentemente declinó. Narashima Rao, quien había sido ministro de Indira y Rajiv, fue nominado jefe del partido. Esta fue la segunda vez (la primera vez fue Shastri en 1964) que la dirección del partido recayó en un individuo que no era miembro de la dinastía Gandhi.

Tras las elecciones de 1991 el Partido del Congreso pudo formar una coalición que permitió a su nuevo líder Narashima Rao ser nombrado primer ministro. Al asumir Rao, el gobierno mantenía impagos sus compromisos de servicio de deuda a organismos multilaterales. Estos se negaban a dar un nuevo financiamiento a menos que Delhi debilitara el sistema de licencias, admitiera la inversión extranjera y redujera el gasto público.

Rao nombró a Manmohan Singh en la cartera de Economía, un académico y funcionario de prestigio. El nuevo ministro devaluó la rupia y aumentaron inmediatamente los ingresos por exportaciones. A continuación, Rao y Singh emprendieron un programa de liberalización que en los años 1990 fue desmantelando varios de los elementos esenciales de la política económica de las cuatro décadas previas (como veremos en la sección 7).

Al presentar el presupuesto anual en julio de 1991, Singh citó a Víctor Hugo, expresando: «Ningún poder en la tierra puede detener una idea cuyo momento ha llegado», refiriéndose al surgimiento de India como una potencia económica, con una presencia global (Rachman, 2011, p. 83).

El gobierno de Rao efectuó un importante repliegue de la presencia del Estado en la economía y aflojó la regulación de la misma, pero no subsanó el descuido de la política económica en áreas clave como la educación y la salud. Como consecuencia

9 Retiró al Partido del Congreso de la coalición de gobierno a la que había entrado recientemente. 
de este descuido, del agravamiento del conflicto de Ayodhya (que veremos en la próxima sección) y de acusaciones de corrupción, la coalición del Congreso fue derrotada en las elecciones de 1996.

\section{El avance del BJP y su alternancia con el Partido del Congreso}

El BJP (Bharatiya Janata Party), Partido del Pueblo de la India, representante del nacionalismo hindú, fue el partido más votado en las elecciones de 1996. Entre 1996 y 1998 consiguió formar dos coaliciones de gobierno que tuvieron una breve duración. En 1999 organizó la Alianza Democrática Nacional y pudo mantenerse en el gobierno por un período completo.

Miremos brevemente los antecedentes. El BJP, creado en 1980, es un partido dirigido por las clases medias hindúes que se ubica en la derecha del espectro político, por sus posiciones frente a la intervención del Estado en la economía y las medidas redistributivas.

La suerte del partido cambió mucho en la década de 1980, a medida que avanzaron las dificultades del Partido del Congreso en el gobierno, pero esto no se reflejó inmediatamente en las urnas. El ascenso del BJP se hizo notable en las elecciones de 1991, coincidiendo con la declinación de la dinastía Gandhi, cuando duplicó su votación de la elección anterior, ascendió al $20 \%$ y se situó como una fuerza nacional. La mejora del BJP fue impulsada por la exacerbación del nacionalismo hindú, sobre todo debido al conflicto hindú-musulmán en torno al templo de Ayodhya.

En el ámbito social, fue muy importante para el ascenso del hinduismo el hecho que desde mediados de la década de 1980 la televisión estatal efectuó la transmisión de versiones de los dos poemas épicos más importantes del hinduismo (Mahabharata y Ramayana), generando una recepción extraordinaria (Flavoni, 2003, p. 257).

El BJP mantiene estrechos vínculos con la RSS, Asociación Nacional de Voluntarios, que es un paraguas de asociaciones nacionalistas hindúes. Los principios del BJP se resumen en el concepto de Hindutva, que significa ser hindú y mantener la cultura india por encima de la occidental. El eje RSS-BJP persigue, abiertamente en el caso de la RSS, hacer de la India una nación hindú.

La RSS nació para proteger los derechos de los hindúes frente al gobierno colonial británico y a las minorías hindúes en regiones de mayoría musulmana. Se convirtió en el motor del nacionalismo hindú, al destacar la lucha histórica de la India contra el dominio de musulmanes e ingleses. En este sentido, se encarga de difundir los valores del nacionalismo y promover la educación y el adoctrinamiento de cuadros así como su adiestramiento físico y militar. Se halla en el centro de una vasta familia 
de organizaciones en los medios de comunicación, universidades, sindicatos, y en el ámbito rural.

El nacionalismo hindú va mucho más allá del Swadeshi del Partido del Congreso, que consistía en promover la industria y los productos nacionales. Plantea volver a hacer grande a la India recuperando los principios que la engrandecieron y que después, según percibe, fueron abandonados haciendo posible el sometimiento del país al dominio extranjero.

Es un nacionalismo de derecha, como hemos precisado, pero no conservador ni esencialmente religioso; por ejemplo, rechaza el sistema de castas viéndolo como una barrera a la unidad nacional. Busca crear un estado industrializado y fuerte, homogéneo, unido por una lengua, una cultura y una religión comunes. Aspira a forjar una identidad hindú más amplia que la que proporciona la casta (Flavoni, 2003, pp. 256 y 276$)$.

En la década de 1980 los gobiernos del BJP, en varios estados, impulsaron reescribir los textos de historia de la India con un sesgo nacionalista y cambiar los nombres de grandes ciudades a su versión vernácula, como en los casos de Bengaluru (Bangalore), Chennai (Madras), Kolkata (Calcuta) y Mumbai (Bombay).

La disputa por el templo de Ayodhya fue el centro de la política india entre 1986 y 1993. En Ayodhya, en el norte de la India, se cree que nació Rama, el héroe del Ramayana, encarnación de Vishnu y una de las deidades más populares del hinduismo. Allí se construyó en el siglo XVI una mezquita, según los hindúes demoliendo un templo a Rama. Este hecho originó disputas entre hindúes y musulmanes, hasta que tras la independencia se optó por cerrar el lugar al culto de ambas religiones.

En 1986, un tribunal decretó la reapertura al culto hindú del lugar. Ese mismo año, el VHP, Consejo Mundial Hindú, asociado a la RSS, inició una campaña para demoler la mezquita y construir un templo a Rama, proclamando que con esto se afirmaría la identidad hindú de la India. El BJP, por su parte, aumentó significativamente su volumen electoral apoyando esta causa y se plegó formalmente a ella en 1989.

En 1992 los hindúes conducidos por el BJP destruyeron la mezquita en Ayodhya y provocaron el estallido de la violencia religiosa en todo el país. El gobierno federal, a cargo del Partido del Congreso, destituyó a los gobiernos de varios estados que apoyaron la violencia del lado hindú e incluso encarceló brevemente a varios líderes nacionales del BJP por su alineamiento abierto en el conflicto.

Como hemos señalado, después de dos gobiernos breves, de coaliciones débiles lideradas por el BJP, este logró formar una coalición fuerte, la Alianza Democrática Nacional en 1999. A.B. Vajpayee asumió como primer ministro y fue el primer 
estadista que sin ser del partido del Congreso pudo completar un período de cinco años. Dentro de esta coalición de centro, el BJP se vio obligado a moderar las posturas del nacionalismo hindú. Sin embargo, volvió a encenderse el conflicto de Ayodhia.

En 2002 se produjo una batalla campal entre hindúes que regresaban de Ayodhya y musulmanes en el estado de Gujarat, de la que se culpó a los musulmanes. En los días siguientes, en toda la India la violencia de hindúes, lanzando proclamas de la derecha, acabó con las vidas de unos dos mil musulmanes y arrojó una mancha sobre el gobierno de Vajpayee.

En lo económico, el gobierno del BJP, que unos años antes preconizaba la autosuficiencia económica, optó decididamente por la globalización, priorizó la apertura y el crecimiento sobre el bienestar. Lanzó un gran proyecto carretero para unir las principales ciudades de la India (El Cuadrángulo Dorado) ${ }^{10}$, prosiguió una agresiva campaña de privatización de empresas públicas y mejoró la acogida a la inversión extranjera, la cual aumentó significativamente.

La política económica del BJP ganó el apoyo de las clases medias y de la juventud, pero despertó acusaciones de descuidar a los pobres y favorecer a las empresas. Asimismo, al igual que el Partido del Congreso, el BJP fue dañado por un escándalo de corrupción en el sector defensa en 2001.

El BJP puso atención en la inserción internacional de India pero descuidó las responsabilidades del gobierno en los servicios públicos. El crecimiento vino acompañado de un aumento de la desigualdad. Las ganancias fueron al 5\% más rico de la población mientras que los demás grupos se estancaron.

Una coalición liderada por el Congreso ganó las elecciones de 2004. Sonia Gandhi, jefa del partido, sorpresivamente declinó el premierato y eligió a Manmohan Singh para el cargo, un impecable tecnócrata, acreditado por las reformas que hiciera como ministro entre 1991 y 1996. Este fue el primer jefe de gobierno que pudo cumplir dos períodos completos apoyado por una coalición del partido del Congreso.

Bajo su mandato se registró un alto crecimiento, que llegó a 9\% en 2007. La India quedó como la segunda economía grande de más rápido crecimiento en el mundo, detrás solamente de China. Se realizó avances en salud, especialmente rural y en educación rural así como en educación superior técnica y en la promoción del empleo rural.

10 Uniendo las ciudades de Delhi, Kolkata, Chennai y Mumbai. 
Singh supo mantener una consistente imagen de honradez en su gobierno. Conducía un Maruti 800, uno de los autos más económicos del mercado. Por la calidad de su gestión como primer ministro se le comparaba con Nehru.

En las elecciones de 2009, la coalición del Congreso obtuvo una contundente victoria apoyando un segundo período de Singh, por encima de una alianza dirigida por el BJP. En la campaña, Rahoul Gandhi, hijo de Sonia y Rajiv, representante de la dinastía, fue la figura central.

En su segundo período, desde 2009, a Singh se le acusó de tolerar la corrupción y se le criticó haberse dedicado a preparar el camino para el ascenso de Rahoul Gandhi a la jefatura del gobierno (retribuyendo los esfuerzos de este en 2009).

Después de once años de gobierno de la coalición del Congreso (liderada por Singh), en 2014 se impuso nuevamente una alianza encabezada por el BJP y su líder Narendra Modi. Ganaron las elecciones prometiendo profundizar las reformas liberales pero hasta ahora no han podido colmar las expectativas que generaron. Esto se ha debido, aparentemente, a la oposición del Partido del Congreso en el parlamento como a cálculos del propio Modi en el sentido de no alienar a los votantes pobres y del campo que determinaron la derrota del BJP en 2004. En cambio, el gobierno muestra rasgos de autoritarismo, de la mano con el fomento del nacionalismo hindú (Dhume, 2016).

Afirma Maya Chadda que los gobiernos de coalición que han dirigido la India desde 1991 (se refiere a los conducidos por Rao, Vajpayee y Singh, respectivamente) han tenido un desempeño general bastante superior a los gobiernos a cargo del partido del Congreso hasta 1989 y han conseguido mejores resultados frente a los principales desafíos que enfrenta el Estado indio, entre ellos los del avance económico, el nacionalismo hindú y las nuevas clases medias (Chadda 2015, pp. 246-7). Estas coaliciones han sido lideradas por el partido del Congreso (dos de ellas) y el BJP (dos también, si incluimos la del actual gobierno de Modi) e incluyen un importante componente de partidos regionales.

\section{La dimensión económica}

\section{Los frutos del desarrollo}

Tal como lo señalan Hardgrave y Kochanek, la experiencia de desarrollo de la India desde la independencia ha puesto en dificultades a postulados centrales de las teorías de la modernización, el desarrollo y la dependencia (Hardgrave y Kochanek, 1993, p, 15). Esto ha ocurrido porque la India ha logrado grandes avances no solo en institucionalidad política sino especialmente en desarrollo económico siguiendo una 
vía propia, ecléctica, audaz y flexible. En este último terreno ha resistido en muchos casos las prescripciones de think tanks y organismos internacionales impartiendo, en cambio, lecciones prácticas con sus logros. En su avance ha conservado muchos rasgos de la situación social que algunos denominan «subdesarrollo», poniendo en entredicho, con los contrastes y contradicciones de su situación, la convencional tipología de los países de acuerdo con su grado de desarrollo.

La India es un país agrícola y rural ( $72 \%$ de población rural), con un vasto sector tradicional de estructuras arcaicas y economías de subsistencia, con una deficiente infraestructura y sectores urbanos en decadencia. A la vez es una gran potencia económica, generadora y exportadora de servicios y alta tecnología, con una formación anual de tecnólogos e ingenieros varias veces superior a la de EE.UU. y con una enorme clase media medianamente educada y vorazmente consumidora.

Durante la primera mitad del siglo XX, de 1900 a 1946, como colonia británica, el producto nacional de la India creció a una tasa de $0,7 \%$ anual en tanto que la población lo hizo a una tasa de $0,8 \%$, manteniendo así estancado el ingreso per cápita.

Desde la independencia, entre 1950 y 1991, el crecimiento económico promedio fue de 3,9\% y la población se incrementó a razón del 2,2\%, con lo cual se consiguió una mejora del $1,7 \%$ anual en el ingreso per cápita. Sin embargo, por sus avances en educación y salud, India se situaba en una posición internacional bastante mejor que la que le daba su ingreso per cápita (Hardgrave y Kochanek, 1993, pp. 21-22).

El modelo de desarrollo que habría de adoptar la India se debatió intensamente entre 1947 y 1956. La tendencia socialista que prevaleció tuvo notable fuerza hasta la década de 1970. En los años 1980 el socialismo se debilitó un tanto y desde la década de 1990 se fortalecieron las fuerzas liberalizadoras, aunque manteniendo elementos estatistas.

El proceso de desarrollo se inició en 1951 cuando se creó la Comisión de Planificación. También se promulgó una primera ley de regulación de la economía a base de un sistema de licencias y permisos que demandaba autorización del gobierno para numerosas operaciones de comercio exterior, inversión y producción.

El Primer Plan Quinquenal de Desarrollo (1951-1956) tuvo objetivos relativamente modestos, básicamente de reconstrucción de los daños causados por la Segunda Guerra Mundial y la partición del país a la agricultura y la infraestructura.

El Segundo Plan (1956-1961) marcó el inicio de una fase de entendimiento y acomodo del gobierno con el capital nacional. Estuvo dirigido por el célebre economista indio P.C. Mahalanobis. Se considera que estableció el modelo de desarrollo del país, sin la influencia de ningún economista occidental (Little, 1982, p. 50) y propició una década dorada de desarrollo hasta 1966. 
El plan dividió los sectores de la industria entre el Estado, las empresas mixtas y la inversión privada. Definió el rol del Estado y los objetivos de autosuficiencia nacional así como el equilibrio entre los sectores público y privado, este último a través de un sistema revisado de licencias, cuotas y de control sobre la inversión extranjera. Siguiendo el modelo soviético, se privilegió la producción de acero y de bienes de capital. Al mismo tiempo, se incrementó la producción de granos en más de 10\%, aunque no se pudo superar la condición de India de importadora de alimentos.

Una de las razones para privilegiar el sector de bienes de capital era un «pesimismo respecto a la exportación» (export pessimism) que asumía que los mercados mundiales crecerían lentamente, que los términos del intercambio perjudicarían a las exportaciones primarias de India y que el país no podría volverse competitivo en la producción de manufacturas sin haber pasado por un largo período de proteccionismo. Esta visión del sector de bienes de capital así como de la función del Estado se mantuvo consistentemente en India hasta mediados de la década de 1980 (Griffin, 1999, p. 118).

El Tercer Plan Quinquenal (1961-1966) representó la más alta expresión de la planificación india. Acabó de dotar al país de un sector industrial moderno y lo convirtió en la sétima potencia industrial del mundo (Wolpert, 1997, p. 362). Al mismo tiempo, se estableció en 1962 los requerimientos nutricionales mínimos para la población.

Se considera que la Revolución Verde, un espectacular aumento de la producción de cereales, comenzó a mediados de la década de 1960, después de la fase de reformas estructurales en el campo y debido a la experiencia de duras sequías en 1965 y 1966. En realidad, ya en 1953 se había introducido variedades de cereales de alta productividad y nuevas técnicas agrícolas. En la década de 1960, con la ayuda de la Fundación Ford estas mejoras se intensificaron, en tanto que en la década de 1970 los frutos de la Revolución Verde se hicieron palpables cuando India se volvió autosuficiente en alimentos.

La aplicación del Cuarto Plan se retrasó por los estragos económicos causados por las guerras con China (1962) y Pakistán (1965). Indira lo lanzó en 1969, lo que mostró una nueva orientación de crecimiento y estabilidad hacia el logro de la autosuficiencia a través de un mayor control del Estado sobre la economía.

Después de incrementar la producción de alimentos, se comenzó a buscar la satisfacción de las necesidades básicas de las masas rurales. En la campaña de la elección de 1971, Indira lanzó un programa de erradicación de la pobreza, que dio origen a esquemas para aumentar el ingreso de los pobres ofreciéndoles trabajo y pago en alimentos.

En este período la economía sufrió los impactos del alza mundial de los precios del petróleo (1973). En lo interno, el gobierno emprendió una ola de nacionalizaciones y 
una mayor regulación del sector privado, en particular del capital extranjero a través de la ley FERA (Foreign Exchange Regulation Act), la cual internacionalmente se convirtió en un modelo para el tratamiento a la inversión externa en la década de 1970. Pese a los problemas mencionados, la economía india creció a un ritmo de $3,4 \%$, aunque sin alcanzar la meta propuesta.

El Quinto Plan (1974-1979) buscó realizar amplias reformas económicas y sociales, en particular mejorar el consumo de los pobres, a través de la estrategia de las necesidades básicas. Dentro de la estrategia, se estableció en la India las necesidades calóricas mínimas de la población en los medios rural y urbano.

Pese a los problemas políticos de la Emergencia decretada por Indira y a que entre 1977 y 1980 gobernó otro partido, el Janata, la economía superó la tasa de crecimiento prevista y registró un 5,2\% anual que permitió resolver los problemas derivados de las crisis mundiales de la primera mitad de la década de 1970. Fue el primer quinquenio en el que se consiguió elevar el ingreso per cápita de la población. Al mismo tiempo, los buenos resultados de la Revolución Verde, animaron al gobierno a ensayar desde 1975 algunas medidas de liberalización de la economía (Chadda, 2015, p. 102).

El Sexto Plan (1980-1985), el último bajo la administración de Indira, fue el más sofisticado en su diseño y el más exitoso en sus resultados. Partiendo de una economía muy débil, por la recesión mundial de 1980, arrojó una tasa de crecimiento anual de $5,7 \%$.

En este plan ya se hizo evidente un cambio de orientación en la acción económica del Estado. Se disminuyó el énfasis a los programas sociales, se limitó el gasto público; se desrreguló y liberalizó el mercado de capitales; y se aflojó las restricciones a las importaciones de insumos para las industrias de exportación de alta tecnología. En el sector rural, se fomentaron el empleo y la redistribución así como la creación de activos.

El Sétimo Plan (1985-1990) fue lanzado en la administración de Rajiv Gandhi, tras el asesinato de su madre (1984). Rajiv siguió la tendencia desrreguladora del plan anterior pero no se atrevió, por razones políticas, a emprender un proceso de privatización de empresas públicas. El plan aumentó el financiamiento externo, con el cual expandió notablemente las exportaciones. Esto potenció visiblemente la tasa de crecimiento y consiguió que por primera vez la producción industrial excediera las proyecciones de un plan quinquenal, con una tasa de $8,5 \%$.

Se apreció que las inversiones en infraestructura de los gobiernos de Nehru e Indira comenzaban a generar beneficios. Al mismo tiempo, sin embargo, un excesivo endeudamiento provocó la histórica crisis de 1991, la cual motivó un radical giro en la política económica del gobierno y el inicio de una nueva fase de crecimiento. 
Bajo la dinastía Gandhi, India adoptó la que era tal vez la única herramienta que podía llevarla al desarrollo, la planificación estatal. Gracias a ella se convirtió muy rápidamente en una potencia industrial y echó las bases para una adecuada provisión de recursos humanos en ciencia y tecnología. También consiguió importantes avances en el alivio de la pobreza y la expansión del empleo. Sin embargo, el aumento de la población $(2,2 \%$ anual entre 1950 y 1991) anuló muchas veces los beneficios del crecimiento económico y la corrupción de las burocracias estatales mermó los beneficios de los programas económicos del gobierno.

Un hecho notable en la década de 1980 fue la aparición de nuevos sectores de la clase media india, que demandaban una mayor y más diversificada producción de bienes y servicios, la cual resultaba problemática por la limitada inversión nacional y la planificación y regulación de la economía.

\section{El salto de la liberalización}

Entre 1989 y 1991, la crisis del bloque soviético y la Guerra del Golfo causaron desajustes severos en la economía india que reclamaron un financiamiento externo para el presupuesto nacional ${ }^{11}$. Al asumir Rao, en 1991, con el Partido del Congreso, el gobierno mantenía impagos sus compromisos de servicio anual a organismos multilaterales. Estos se negaban a dar un nuevo financiamiento a menos que Delhi debilitara el sistema de licencias, admitiera la inversión extranjera y redujera el gasto público.

Rao nombró a Manmohan Singh en la cartera de Economía, un académico y funcionario público que tenía además una amplia experiencia internacional y conocía de cerca las exitosas políticas económicas de los «dragones» asiáticos. Singh devaluó la rupia y aumentó inmediatamente los ingresos por exportaciones. A continuación, Rao y Singh emprendieron un programa de liberalización que en los años 1990 fue desmantelando varios de los elementos esenciales de la política económica de las últimas cuatro décadas ${ }^{12}$.

Se abolió las licencias en casi todas las ramas industriales, incluyendo los topes de producción en automóviles y artefactos domésticos. Los derechos de importación cayeron del 71\% del valor de las mercaderías en 1993 al 35\% en 1998. Los inversionistas extranjeros fueron autorizados a tener hasta un $51 \%$ del accionariado de empresas.

\footnotetext{
11 Más específicamente, los desajustes fueron causados por la caída del comercio con el bloque soviético y la ayuda de la URSS, así como el alza de los precios del petróleo en 1991 y la repatriación de 130000 indios que trabajaban en los países del Golfo y eran una fuente importante de remesas.

12 Las reformas tuvieron continuidad en el gobierno del BJP, 1999-2004
} 
Uno de los cambios más dramáticos ocurrió en el sector automotor, donde en 1991 tres compañías producían 190000 vehículos mientras que en 2001 diez fabricantes, la mayor parte con inversiones conjuntas, produjeron 500000 automóviles. En el sector público, se permitió que los inversionistas privados pudieran ser propietarios de hasta $74 \%$ del accionariado de empresas no estratégicas. Al mismo tiempo, la inversión privada fue autorizada a competir con las empresas públicas en sectores como transporte aéreo de pasajeros, telecomunicaciones, banca y producción de acero y de carbón, rompiendo los monopolios gubernamentales (McLeod, 2002, pp. 180-181, Rachman, 2011, p. 83).

La tasa de crecimiento económico se disparó en la década de 1990, superándose la relativamente modesta "tasa hindú de crecimiento" de décadas previas. Se habló de un «milagro» indio con tasas de 8,5\% entre 1992 y 1995 (Ortiz, 2010, p. 31).

La crisis asiática de 1997-1998 solo afectó moderadamente a la India, haciendo bajar dos puntos el crecimiento en 1997 (Rosser y Rosser, 2004, p. 475). Las exportaciones se expandieron a una tasa de $27 \%$ a mediados de los noventa. La industria de software se desarrolló hasta alcanzar a representar el 2000 el 15\% del total de exportaciones del país. Entre 1996 y 1998 India desplazó a Alemania para convertirse en la cuarta economía del mundo (detrás de EE.UU., Japón y China) (McLeod, 2002, pp. 180-181).

Sin embargo, las reformas de la década de 1990 no liberalizaron ni modernizaron completamente la economía india. La inversión extranjera quedó todavía muy por debajo de la registrada en otras economías emergentes, notablemente la china. En muchos casos los gobiernos de estados manejados por el nacionalismo hinduista cancelaron las inversiones extranjeras autorizadas por el gobierno federa ${ }^{13}$. También subsistían algunas restricciones a la exportación de materias primas, con el objeto de mantener sus precios bajos para el consumo interno, así como restricciones al comercio agrícola a nivel de estados y aun de distritos.

La privatización tenía un largo camino por avanzar, con millones de burócratas en la administración y supervisión de empresas públicas. Estas empresas eran destinatarias a su vez de importantes subsidios. La flexibilización laboral era una reforma pendiente, que recién comenzaría a plantearse en el gobierno del BJP, en 2001. La infraestructura del país, particularmente carreteras, puertos y energía eléctrica, era muy deficiente. Finalmente, la reforma tributaria aparecía como un desafío inmenso, con solo 12 millones de contribuyentes al impuesto a la renta ${ }^{14}$, una gran dosis de evasión,

\footnotetext{
13 Rosser y Rosser (2004, p. 474) mencionan los casos de compañías como Kentucky Fried Chicken, Coca Cola, Pepsi Cola, Bechtel y Enron.

14 En 1997 según McLeod (2002, p. 182).
} 
ingresos agrícolas exonerados y una masa de pobres que simplemente no podían contribuir. Con las reformas de la década de 1990, la pobreza disminuyó de 35\% a $30 \%$ en las ciudades pero se mantuvo inalterada en el campo (Rosser y Rosser, 2004, p. 475).

En el siguiente gobierno, de la alianza del BJP (1999-2004), que representaba los intereses de las prósperas clases urbanas, las reformas continuaron y el crecimiento se centró en las tecnologías de información y los servicios de procesamiento de negocios (call centers). El gasto público se redujo en las sensibles áreas de salud y educación.

En lo económico el gobierno del BJP optó por la globalización y priorizó el crecimiento sobre el bienestar. Lanzó un gran proyecto carretero para unir las principales ciudades de la India (El «Cuadrángulo Dorado»). Llevó a cabo también una agresiva campaña de privatización de empresas públicas, y dio una mayor acogida a la inversión extranjera, que aumentó considerablemente.

Bajo el gobierno de M. Singh, 2004-2014, se dio un elevado crecimiento que llegó a $9 \%$ en 2007. India quedó como la segunda economía grande de más rápido crecimiento en el mundo, detrás solamente de China. Se realizó la reforma de los sistemas financiero y bancario y del sector de empresas públicas. Se continuó el ambicioso programa de carreteras del BJP, pero también se registró logros en salud, especialmente rural y en educación rural así como en educación superior técnica; se promovió también el empleo rural. Se decretó que parte de las ganancias de las compañías debían invertirse en proyectos sociales.

El actual gobierno indio, a cargo del BJP desde 2014, pese a sus promesas electorales de profundizar las reformas liberales, hasta la fecha no ha podido concretar mayores cambios en la política económica. Ha aumentado el aliento a la inversión extranjera pero no ha logrado cambios significativos en el trato burocrático de la misma. Impulsó la flexibilización de las regulaciones laborales pero la implementación viene siendo lenta a nivel de los estados. Por último, no ha derogado controvertidas medidas de la administración de Manmohan Singh, tales como los impuestos retroactivos a las empresas ni la reinversión de las ganancias corporativas en proyectos sociales. Por el contrario, ha incrementado los fondos para la promoción del empleo rural, consciente del caudal de votos que está en juego (Dhume, 2016).

Entre 1992 y 2011, la economía india registro un crecimiento promedio de 7\% anual. Los servicios pasaron a representar 50\% del PBI, el doble que la industria. Entre 2000 y 2006 las exportaciones se incrementaron en 200\% y subieron de 22\% a 35\% del PBI (Purcelli, 2008, p. 21). 
Un fenómeno saltante es que en los años 1980 ha surgido una llamada «nueva clase media» en la India, de 200 a 250 millones de personas ${ }^{15}$. En realidad, por sus ingresos, este sector está dentro del $20 \%$ superior de la población. Sus miembros no pertenecen a las clases más altas tradicionales pero tienen un nivel de vida más elevado que estas. Exhiben en común hábitos de consumo y preferencias por ciertas modas y películas; hablan lenguas regionales pero utilizan el inglés por razones de moda. No solo tienen un consumo muy alto sino también una creciente tasa de ahorro.

A manera de ilustración, el 20\% superior recibe 46\% del ingreso nacional. El segundo quintil recibe $20 \%$ del ingreso. Y el tercer quintil, que sería realmente el de la clase media, recibe $15 \%$ del ingreso nacional, con lo cual es un sector desfavorecido en la distribución.

A esta "nueva» clase media se le diferencia de la «antigua» clase media, la cual mantiene los valores nehruvianos, posee educación universitaria y maneja habitualmente el inglés, siendo sobre todo profesionales o funcionarios públicos. Esta antigua clase media desdeña a la nueva clase media, a la que considera vulgar y sin educación.

Por su producto nacional, de acuerdo con la paridad de poder adquisitivo, la India es hoy la tercera economía del mundo, detrás de China y EE.UU. En cambio, por su índice de desarrollo humano $(0,609)$, la India ocupa el puesto 130, en tanto que China se halla en el puesto 90 y EE.UU. en el puesto 8 (CIA, 2015).

El desarrollo humano de India (sus indicadores de expectativa de vida, educación, e ingreso per cápita) la coloca en un nivel internacional que el PNUD considera intermedio. En comparación, Pakistán muestra un índice $(0,538)$, que lo sitúa en el puesto 147 y en un nivel bajo, mientras que el promedio de Asia del Sur es de 0,588 (UNDP, 2015).

En cuanto a pobreza, India tiene a un $12,4 \%$ de su población bajo la línea internacional de pobreza (2012) frente a China con $11,18 \%(2010)^{16}$. En contraste, la desigualdad económica en India es bastante moderada, ocupando el puesto 48 en el mundo con un índice Gini de 0.368. Estados Unidos exhibe una mayor desigualdad, situándose en el puesto 77 con 0,45, mientras que el Estado comunista de China es el más desigual de los tres, en la posición 89 con $0,473^{17}$.

\footnotetext{
15 Esta reseña de la nueva clase media se basa en Rothermund (2008, capítulo 15).

16 Esta línea es de US\$ 1,90 al día utilizando la paridad de poder adquisitivo (2011). World Bank (2015), World Development Indicators.

17 A base de CIA, World Factbook 2014-15, donde se considera cifras de 115 países en orden descendente de desigualdad. Nosotros hemos invertido el orden, poniendo primero a los países menos desiguales. Recordemos que el índice Gini refleja a menor valor menor desigualdad. Las cifras corresponden a India (2004), EE.UU. (2007) y China (2004).
} 
La expansión demográfica de India, que en el pasado significó muchas veces la cancelación de los beneficios del crecimiento económico, parece haber cambiado de signo a partir del siglo XXI. Los jóvenes que entran a trabajar tienen que hacerse cargo de la manutención de un menor número de dependientes, con lo cual pueden incrementar su ahorro.

En 2001 un 60\% de la población estaba en el grupo laboralmente activo de 15 a 64 años de edad, mientras que un 35\% tenía menos de 15 años. Para 2026, se estima que la gente en edad de trabajar será un $69 \%$ de la población mientras que los de edad dependiente habrán disminuido a $23 \%$. De esta manera, el llamado «bono demográfico» beneficiará a la economía india por un buen tiempo, hasta que llegue el momento que la población mayor de 64 años crezca y el bono se torne negativo (tal como sucede actualmente en Europa occidental y Japón) (Rothermund, 2008, capítulo 13).

\section{La dimensión externa}

\section{La política exterior hasta 1990: el no alineamiento, Pakistán, China y la URSS El no alineamiento}

En las décadas previas a la independencia, Nehru estuvo a cargo de las relaciones internacionales en el Partido del Congreso. Se hallaba convencido de que la obtención de la independencia de la India se vinculaba estrechamente con la evolución política internacional y dedicaba especial atención a esta. Así, por ejemplo, en 1927 asistió en Bruselas al Segundo Congreso de la Liga contra el Imperialismo y unos meses antes de la independencia, en 1947 convocó en Nueva Delhi a una Conferencia sobre Relaciones en el Asia a la que asistieron veinticinco naciones.

Después de la independencia, Nehru pensó fundamentalmente que la India debía desarrollar una política exterior autónoma. El marco conceptual que encontró para sustentar este curso en la primera década de vida de la India fue el No Alineamiento, es decir el mantenimiento de una posición general de distancia de las dos superpotencias y sus bloques antagónicos, que se acababan de definir con el inicio de la Guerra Fría. El no alineamiento no impedía inclinarse a uno u otro bando en temas específicos pues no era equivalente a neutralidad.

Nehru temía que de tomar partido la India por uno de los dos bloques provocaría la hostilidad de la superpotencia contraria y al mismo tiempo correría el riesgo de volverse cliente y ser eventualmente dominado por la superpotencia cuyo bando escogiera. Igualmente, en caso de una gran conflagración, la India se vería envuelta en esta. Estas posibilidades atentaban contra el interés principal de la India que era 
el de dedicar sus esfuerzos al desafío mayúsculo de convertirse en un estado-nación moderno e influyente (Chakraborty, 2016, p. 26).

Apropiadamente para la que había sido la primera colonia en obtener la independencia después de la guerra, Nehru asoció esta posición con la lucha contra el colonialismo y el imperialismo, la cual era una de las corrientes morales con mayor fuerza en ese momento en la escena internacional. En este sentido, planteó la democratización de las relaciones internacionales, en procura de revertir el predominio de las potencias occidentales. También colocó a la India en una posición de vanguardia en una cruzada de búsqueda de la paz internacional y el desarme nuclear, invocando el legado de Gandhi (quien alcanzó a conocer los horrores de Hiroshima y abogó por la erradicación de la bomba atómica) y ganando el apoyo en esta causa de figuras mundiales como Bertrand Russell y Albert Einstein. Algunos autores afirman que en la década de 1950 la prominencia internacional de India se debió más a Nehru que al peso mismo de la India (Rose, 1976, p. 218).

La Conferencia de Bandung (1955) marcó el comienzo de un movimiento de solidaridad afroasiática, del cual surgiría el No Alineamiento (NoAl). Un año después, la reunión de Nehru, Nasser y Tito en la isla de Brioni (1956) sentó las bases del NoAl. En tanto que el primer movimiento implicaba un grado de coordinación entre los Estados, el segundo solamente exigía la abstención de alineamiento militar con una de las dos superpotencias.

La Conferencia de Belgrado (1961) fue el comienzo formal del movimiento No Alineado. El año siguiente, el ataque chino a la India (1962) acabó tempranamente con la solidaridad afroasiática.

El movimiento No Alineado se sustentó en la conducción de Nehru, Nasser y Tito además de Sukarno de Indonesia, dando a estos líderes una gran visibilidad internacional y una presencia moral, alentando las luchas de liberación nacional así como el desarme nuclear. Nasser representaba el renacer del mundo árabe, Tito una forma de comunismo independiente de la URSS y Sukarno un baluarte de la lucha antiimperialista y nacionalista muy cercano a Nehru desde los ańos 1920.

Pese a su formal rechazo a la violencia, Nehru llevó a la India a una importante intervención militar en el enclave de Goa en el subcontinente (1961) y expulsó a los portugueses de su posesión colonial después de infructuosas negociaciones. Rothermund señala que Nehru actuó ante cierta presión de las naciones africanas que reclamaban de la India un ejemplo de lucha antiimperialista (Rothermund 2008, p. 47). 


\section{Guerra con China, 1962}

La temprana guerra con Pakistán por Cachemira había dejado a la India con un vecino en pie de guerra. Pakistán se alineó con EE.UU. para contrapesar la mayor capacidad bélica de India y Washington le dio ayuda militar desde 1954, lo que exacerbó la percepción india de una amenaza a su seguridad. Pakistán se sumó al Pacto de Bagdad (1955) y luego a CENTO ${ }^{18}$ (1958).

En esta situación, India puso cuidado en la relación con China para evitar tener otro vecino hostil. Por lo demás, Delhi sabía que en caso de un conflicto le sería difícil repeler un ataque chino por sí sola y tendría que recurrir a Occidente y renunciar al NoAl.

En 1954, al suscribir un acuerdo con China sobre comercio en el Tibet, India aceptó la ocupación china de este territorio. En el acuerdo se incluyó los principios de coexistencia pacífica (Panchshila) que ambos esperaban difundir en el Asia.

Sin embargo, en la década de 1950, se fueron haciendo evidentes diferencias y tensiones entre los dos grandes vecinos. China, a través de la extraordinaria figura de su canciller Chou En-lai, competía con India por lograr el liderazgo del No Alineamiento y buscaba convertirlo en un bloque opuesto a EE.UU. India, por su parte, se interesaba por acercarse a la URSS con el fin de contrapesar la incorporación de Pakistán en alianzas con EE.UU.

De esta forma, entre 1956 y 1959, China se sintió mortificada por la ayuda que Moscú ofrecía a Delhi y por la nueva relación que se perfilaba de la URSS con India, la cual no incluía a China.

China objetaba los límites de India con el Tibet, que habían sido establecidos por Gran Bretaña en 1914 (la Línea MacMahon), una discrepancia que no fue resuelta en el tratado de 1954. Desde mediados de la década de 1950 se produjeron escaramuzas en la frontera y varias conversaciones entre los dos vecinos quedaron truncas. India alentó a los tibetanos que se levantaron contra Pekín en 1956, lo que despertó el enojo de China (Diro, 2010, p. 200). Cuando estos fueron derrotados, en 1959, Nehru aceptó el exilio del Dalai Lama, aunque no la creación de un gobierno tibetano en el exilio.

Chou En-lai visitó India en 1961 para negociar el tema fronterizo y ofreció un arreglo a Nehru: China respetaría la Línea MacMahon si India le cedía el paso Karakoram y la zona de Aksai Chin en los Himalayas. El paso era esencial para el acceso de China

18 La Organización del Tratado Central que sucedió al Pacto de Bagdad y vinculó a EE.UU., Reino Unido, Irán, Irak, Pakistán y Turquía. 
a sus provincias occidentales. China ya había ocupado hacia unos años secretamente Aksai Chin, de manera que India no tendría sino que aceptar el hecho.

Nehru rechazó la propuesta. Las escaramuzas fronterizas siguieron hasta que en setiembre de 1962 India movilizó tropas a la frontera. En octubre, cuando la URSS y EE.UU. estaban enfrascados en la Crisis de los Misiles en Cuba, China distrajo a la India con una invasión previa en Assam, montó una masiva operación y capturó, sin mayores dificultades, el paso Karakoram. El canciller indio, Menon, renunció a su cargo por esta aplastante derrota.

Ambos contrincantes mantuvieron en secreto los detalles de la guerra. India no quería admitir sus pérdidas y China no deseaba, por su parte, revelar sus ilegítimas ganancias (Rothermund, 2008, p. 46).

La guerra comenzó y terminó de manera un tanto sorpresiva. China se retiró rápidamente de Assam, cuando India se preparaba para una guerra prolongada en ese escenario. El rotundo triunfo chino trajo consigo una actitud de superioridad de Pekín sobre Delhi (Rothermund, 2008, p. 46).

En realidad, puede pensarse que un importante propósito de China en esta guerra fue disminuir el prestigio de India entre los NoAl. Y en efecto, la guerra de 1962 debilitó las pretensiones de liderazgo NoAl y regional de India (Chadda, 2015, p. 140).

Además de esto, la derrota ante China desmoralizó a Nehru, desnudó las debilidades de su política exterior y disminuyó su popularidad como líder, inclusive en su partido y en el Parlamento. Para mantener el poder, Nehru recurrió a empoderar en estos dos ámbitos a un grupo de influyentes líderes de varios estados que le eran incondicionalmente leales y que fueron denominados el Sindicato (McLeod, 2002, p. 144).

\section{Guerra con Pakistán, 1965}

Una de las primeras medidas que adoptó Delhi después de 1962 fue aumentar su gasto en armas. Esto preocupó a Pakistán, que había tomado nota de la vulnerabilidad del ejército indio. Aparentemente, Pakistán vio entonces una breve oportunidad para atacar a India antes de que esta consiguiera fortalecerse. En este propósito, Islamabad concluyó en 1963 una alianza con China y le cedió territorio al oeste del paso Karakoram.

La muerte de Nehru (1964) facilitó los propósitos de Pakistán, quien quiso probar la resolución del nuevo líder, Shastri, penetrando territorio indio en junio de 1965. La débil reacción india, solicitando un arbitraje británico, fortaleció la determinación bélica de Pakistán, quien habiendo conversado con China, lanzó una ofensiva en setiembre que cortó el acceso de India a Cachemira. 
Esta vez, sin embargo, la reacción india fue rápida y decisiva pues invadió Pakistán por la importante zona de la ciudad de Lahore y se apoderó de territorio. China lanzó un ultimátum amenazando atacar a India por Sikkim pero Delhi lo desatendió y China se abstuvo de actuar, dejando de abrir el segundo frente que había convenido con Islamabad. China, en realidad, quiso alentar un ataque de Pakistán contra India pero no tenía interés en involucrarse en una guerra pues ya había conseguido en 1962 sus propósitos estratégicos en Karakoram.

La URSS organizó una conferencia de paz, en la cual para obtener la devolución del territorio ocupado por India, Pakistán debió asumir el compromiso de no volver a usar la fuerza en el litigio de Cachemira. Fue un triunfo indio, aunque no totalmente convincente, que pudo levantar el espíritu de la derrota de 1962.

\section{La politica exterior de Indira}

La guerra con China, la muerte de Nehru y la guerra de 1965 con Pakistán señalaron un período de transición en la política exterior india.

Con Indira Gandhi, desde 1966, comenzó una nueva fase en la que se dio igual peso a la fuerza que a la diplomacia, se estrechó lazos con la URSS y se puso más énfasis en los asuntos regionales que en los mundiales, tratando de mejorar la capacidad de India de influir sobre su propia región por encima de las potencias externas, señaladamente EE.UU., URSS y China (Chadda, 2015, pp. 143-144).

En la fase anterior, la política de Nehru había dado a India trascendentales ganancias en autonomía y prestigio internacional con su liderazgo del NoAl, pero las acciones de Pakistán y China, sobre todo en el terreno militar, frustraron las pretensiones de Delhi de convertirse en portavoz de los nuevos Estados en el orden internacional.

Después de la guerra con Pakistán, India vivió una mala situación económica, incluyendo dos años de grandes sequías, 1965 y 1966, cuyas consecuencias solo pudieron paliarse con una fuerte ayuda alimentaria de EE.UU. y contribuyeron a crear la imagen de un país plagado por la pobreza.

Indira visitó EE.UU. en 1966 y pidió un incremento de la ayuda alimentaria pero encontró reticencia del presidente Johnson, por las críticas que ella hacía a la intervención estadounidense en Vietnam y por la compra de armamento soviético que el gobierno había emprendido desde 1963.

Este hecho llevó a Indira a pensar en fortalecer no solo militarmente sino también económicamente a la India y en la necesidad de consolidar un cuadro más diversificado en las relaciones del país, robusteciendo las relaciones con la URSS. 
En lo económico, hemos visto que Indira optó por la Revolución Verde. En lo militar, aumentó las compras de armas a la URSS para fortalecerse sin caer en la dependencia militar de EE.UU. A diferencia de Washington, Moscú no le demandaba un alineamiento militar sino solamente abstenerse de aliar al bando contrario.

Bajo Indira se dio un importante acercamiento a la URSS, la cual brindó a la India ayuda económica y militar a través de acuerdos de largo plazo que incluían transferencia de tecnología y acuerdos de coproducción de equipo y armamento militares, satisfaciendo así las intenciones de autosuficiencia de Delhi (Chadda, 2015, p. 141).

La URSS se convirtió en el mayor proveedor de armas de la India. Para muchos, esta proximidad comprometió la postura no alineada de la India, aunque no involucró ni una alianza ni un acercamiento ideológico.

En agosto de 1971, Delhi y Moscú suscribieron un importante acuerdo de paz y cooperación que consolidó el acercamiento entre ambos. Moscú había estado presionando por la firma de este acuerdo pero Indira solamente aceptó hacerlo cuando se encontró en una delicada situación por la secesión de Bangladesh de Pakistán (marzo 1971). El acuerdo dio a la India acceso a avanzadas tecnologías militares y, en lo inmediato una promesa de la URSS de neutralizar a China en caso de que esta decidiera intervenir en el conflicto en defensa de Pakistán. Sin embargo, Moscú aconsejó a India no intervenir en el conflicto.

\section{Guerra con Pakistán, 1971}

Una larga cadena de descontento y protestas de los habitantes de Pakistán Oriental, aduciendo un trato abusivo por parte de las autoridades de Islamabad, llegó a su clímax con el triunfo en elecciones parlamentarias de 1970 de la Liga Awami que representaba las aspiraciones nacionalistas del territorio.

Islamabad rechazó las demandas autonomistas que formuló Pakistán Oriental y anuló las elecciones, arrestando a los líderes de la Liga Awami. Esta reaccionó declarando la independencia de Pakistán Oriental como la República de Bangladesh el 26 de marzo 1971.

Pakistán envió su ejército al este, enfrentó duramente la secesión y ocasionó el éxodo de millones de personas a India. Delhi, por su parte, se dedicó a desplegar una activa diplomacia para conseguir que la comunidad internacional frenara los excesos del ejército pakistaní; también decidió intervenir indirectamente en el conflicto entrenando guerrillas en su territorio.

Pakistán lanzó un ataque aéreo contra India el 3 de diciembre e inició la tercera guerra entre ambos. India, portando el estandarte de una intervención humanitaria, 
respondió con una rápida ofensiva terrestre en el este que hizo capitular a las tropas pakistaníes el 16 de diciembre, capturando 93000 prisioneros de guerra.

La rapidez y efectividad de la ofensiva india canceló una amenazante posibilidad de que EE.UU. interviniera en el conflicto, a través de un portaaviones que había apostado en la bahía de Bengala. En efecto, Nixon planeaba usar esta nave, provista de armas nucleares, si es que la URSS decidía intervenir en el conflicto a favor de India (Rothermund, 2008, p. 48).

A partir de esta guerra, que acabó de revertir los efectos de la derrota de 1962, India quedó como potencia regional en el sur de Asia. Pakistán perdió una buena parte de su territorio, que le daba una valiosa situación estratégica frente a India y vio debilitadas sus pretensiones de paridad militar.

A los pocos años de haber cambiado la orientación de su política exterior, la India, a base de su destreza diplomática y militar, lograba mejorar sustancialmente su posición regional aunque sin llegar a un acuerdo de límites con Pakistán ${ }^{19}$.

Sin embargo, las ganancias del reconocimiento de India como potencia regional se vieron disminuidas cuando ocurrió la invasión de Afganistán en 1979 y el gobierno estadounidense tomó la decisión de convertir a Pakistán en un aliado de primer orden en la reanudación de la Guerra Fría.

Entre 1982 y 1987 EE.UU. proporcionó a Pakistán 3200 millones de dólares en ayuda económica y militar, no obstante las advertencias indias sobre los peligros de esta relación y el evidente rol que Pakistán decidió jugar al promover insurgencias contra Delhi en Cachemira y Punjab (Chadda, 2015, pp. 148-150).

En el lado positivo del nuevo liderazgo regional de India debe contarse la creación de la SAARC (Asociación Regional de Cooperación del Sur de Asia) en 1985. Surgida por una iniciativa de Bangladesh buscando un trato multilateral en las relaciones de India con sus vecinos, Delhi supo acoger inteligentemente la propuesta.

\section{La búsqueda de la bomba atómica}

Nehru tuvo una actitud ambivalente hacia la bomba atómica. Por un lado, la condenaba, como lo había hecho Gandhi y preconizaba el desarme nuclear, pero por otro lado pensaba que India debía poseer la capacidad de producirla ${ }^{20}$.

\footnotetext{
19 En el Acuerdo de Simla (1972) que cerró la guerra, el presidente Bhutto argumentó que resolver entonces el problema de la frontera en Cachemira le costaría perder el gobierno.

20 La reseńa del desarrollo nuclear de India se basa en Rothermund (2008, capítulo 5).
} 
De esta manera, Nehru creó en 1948 la Comisión de Energía Atómica, dirigida por un brillante físico cercano a él, Homi Bhabha. La Comisión, dotada de amplios recursos, operó con poca transparencia. Aunque gran parte del propósito de la Comisión era el desarrollo de usos pacíficos de la energía nuclear, Nehru no quiso vincularse al programa estadounidense de Átomos para la Paz por los controles que conllevaba.

En 1956 India construyó un reactor nuclear y en 1965 logró producir plutonio para su abastecimiento y quedó así, sustentada en sus propios medios, en capacidad de producir una bomba. Bhabha anunció a EE.UU. que India podría tener una bomba a corto plazo, en la creencia de que tanto Washington como Moscú aceptarían la consumación de este hecho, por la reciente conversión de China en potencia nuclear (1964).

La falta de anuencia de Washington, la desaparición de Nehru, la indecisión del nuevo líder indio, Shastri, de realizar una prueba nuclear y la subsiguiente muerte trágica de Bhabha (1966) contribuyeron a cerrar este capítulo del desarrollo nuclear indio sin un fruto culminante.

Los deseos de los científicos indios de culminar los avances que lograra Bhabha se vieron acogidos varios años después, en 1974, cuando Indira Gandhi decidió mejorar su alicaída imagen interna, por los problemas que afligían a su gobierno, autorizando una prueba nuclear. Se habló oficialmente de la prueba de un «artefacto nuclear» para «fines pacíficos». Pero la reacción internacional, liderada por EE.UU., ante la evidente capacidad de India de manejar la fisión nuclear, fue la de negar acceso al país a la tecnología que le pudiera permitir continuar su progreso ${ }^{21}$.

Pese a sus inclinaciones, Indira se abstuvo de realizar nuevas pruebas nucleares en la década de 1980, por el temor de que la reacción internacional resultara contraproducente. Sin embargo, en 1983, inició un programa integrado de misiles guiados que era fundamental para instrumentar el lanzamiento de la bomba.

India alcanzaba de esta manera un nivel de capacidad militar que contribuía a mejorar su estatus a nivel mundial aunque encontraba dificultades para consolidar su avance.

Mientras tanto, a partir de 1974, Pakistán le pisaba los talones a India en su desarrollo nuclear, a partir de la apropiación de tecnología holandesa y de la colaboración de China. En 1987 dejó entrever que tenía ya la capacidad de producir armas atómicas.

\footnotetext{
21 El mismo secretario de Estado estadounidense Henry Kissinger organizó en 1975 en Londres el Grupo de Proveedores Nucleares para este fin.
} 


\section{La política exterior desde la década de 1990: acercamiento con Estados Unidos}

El fin de la Guerra Fría en 1989 trajo para la India el beneficio de disminuir la importancia de Pakistán para Washington, debido al retiro soviético de Afganistán. Sin embargo, la caída de la URSS dejó a Delhi en la urgente necesidad de redefinir los rumbos de su política exterior. La Guerra del Golfo (1991), en la cual India respaldó al derrotado Irak, por sus afinidades seculares y cercanía a la URSS, vino a hacer aún más difícil el panorama.

El primer cambio que adoptó India fue el establecimiento de relaciones con Israel, en 1992, rompiendo una tradición de apoyo a la causa árabe. Israel ya había venido ganando importancia como socio comercial de la India y como proveedor de armas.

Empero, en el plano regional, la situación de Cachemira, donde aumentó la insurgencia alimentada por grupos de mujaidines que habían acabado de combatir a la URSS en Afganistán y eran apoyados por Pakistán, demandaba acciones represivas del ejército indio, las cuales eran mal vistas por Washington e impedían una mejora de las relaciones de Delhi con la única superpotencia.

A pesar de la liberalización de la economía india y de una creciente conexión en el sector de tecnologías de información entre empresas indias y estadounidenses, en lo político, las relaciones Delhi-Washington llegarían a su punto más bajo en 1998 con la realización de pruebas nucleares por India.

En 1998 subió un gobierno de coalición, encabezado por el BJP que nombró a Vajpayee como primer ministro. Este gobierno, relegó un tanto las preocupaciones regionales intentando buscar un rol para la India en la formación de un nuevo orden internacional (Chadda, 2015, p. 248). En el curso de su mandato, hasta 2004, Vajpayee abrazó el nacionalismo, realizó ensayos atómicos y practicó el realismo, acercándose a EE.UU. pero también a Rusia y a China ${ }^{22}$.

En mayo 1998 el gobierno del BJP, que había criticado una política de «ambigüedad nuclear» del Partido del Congreso, autorizó la realización de cinco pruebas nucleares, que ocurrieron en absoluto secreto (Rothermund, 2008, pp. 64-65). Dos semanas después, Pakistán realizó seis pruebas nucleares. Washington y la ONU impusieron fuertes sanciones económicas a ambos Estados. La economía pakistaní se vio seriamente golpeada por el corte de la ayuda estadounidense, pero la economía

\footnotetext{
22 Como consecuencia de estos acercamientos, Rusia reactivó la venta de armas a India en 2000 al renovarse un acuerdo de cooperación técnica y militar, y pasó a ocupar el tercer puesto entre sus proveedores, detrás de EE.UU. y el Reino Unido. Similarmente, el comercio entre ambos países más que se duplicó entre 2004 y 2008. Por otro lado, el comercio de India con China se multiplicó seis veces entre 2002 y 2005, cuando el primer ministro chino visitó Delhi. Poco después Delhi y Beijing decidieron establecer una asociación estratégica.
} 
india apenas fue afectada, por la bonanza que vivía. La particular situación de India comenzó a hacer pensar a Washington en la vía de las negociaciones políticas.

La relación política con Washington mejoró a raíz de la tercera guerra India-Pakistán, en 1999, en la cual el comportamiento de Islamabad enajenó el apoyo estadounidense. El jefe de las fuerzas armadas pakistaníes, general Musharraf, determinó penetrar secretamente territorio indio en la zona de Kargil, Cachemira, aprovechando el invierno. Un temprano deshielo permitió a India descubrir a los invasores y hacerlos retroceder, aunque sin entrar en la zona pakistaní, para evitar un escalamiento del conflicto entre las que eran dos potencias nucleares.

Presionado por el general Zinni, jefe militar estadounidense, Musharraf accedió al retiro de las tropas pakistaníes pero ideó una temeraria estratagema en el plano diplomático, con el objeto de evitar el descrédito personal de hacerse responsable del repliegue. Señaló a su primer ministro, Sharif, que el presidente Clinton tenía un interés personal en el asunto y provocó su visita a Washington, con lo cual el retiro de tropas quedó, aparentemente, como resultado de la entrevista de los dos jefes de gobierno (Rothermund, 2008, pp. 52-53).

La estratagema de Musharraf quedó pronto en evidencia, debilitó la confianza estadounidense en Pakistán y se convirtió en un factor decisivo para la histórica visita que realizó Clinton a Delhi en marzo 2000. En ella expresó su deseo de que India se convirtiera en el mayor socio de EE.UU. en Asia, lo que marcó una extraordinaria inflexión en la relación bilateral. Significativamente, la visita incluyó a la ciudad de Hyderabad, uno de los centros de la industria informática india.

La «Alianza contra el Terror» propuesta por Washington después del ataque a las Torres Gemelas (2001) fue un nuevo motivo para acercar a India y EE.UU., con expectativas de Delhi de que tal cooperación la ayudaría en su lucha contra el terrorismo en Cachemira.

Pero los ataques terroristas continuaron en la India y llegaron a causar una aguda crisis con Pakistán en 2002, que no se convirtió en guerra por una mediación estadounidense $e^{23}$. Esta participación de Washington fue determinante para la iniciación de conversaciones con Delhi, el mismo año, en el campo de la cooperación en seguridad militar.

Los primeros resultados fueron la autorización de Washington de la venta de un sistema antimisiles israelí con tecnología estadounidense, dejando entrever un proceso

\footnotetext{
23 Se trató de un frustrado ataque de terroristas pakistanos al parlamento indio en Delhi que causó la movilización de tropas indias a lo largo de la frontera con Pakistán (Rothermund, 2008, p. 56).
} 
de entendimiento entre EE.UU., Israel e India, así como la cooperación de EE.UU. para la modernización y fortalecimiento de la marina de guerra india, con miras a defender las críticas rutas del océano Índico. En 2004 el gobierno del BJP extendió la cooperación a la esfera civil, específicamente a actividades nucleares, programas espaciales y comercio de alta tecnología.

Estos acuerdos prepararon el camino para la visita del nuevo jefe de gobierno (del Partido del Congreso), Manmohan Singh a Washington en 2005. En ella se hizo un primer esbozo de un acuerdo nuclear que coronaría el acercamiento entre las dos potencias. Se acordó que India, pese a no ser signataria del Acuerdo de No Proliferación Nuclear, sería considerada como una potencia nuclear responsable y tendría acceso a tecnología estadounidense para el uso civil de la energía nuclear. Ese mismo año, EE.UU. consiguió que los países del Grupo de Proveedores Nucleares hicieran una excepción y admitieran a India a sus filas sin haber suscrito el tratado de no proliferación. India era aceptada como la sexta potencia nuclear del mundo.

En 2006, el presidente Bush visitó India y avanzando en la línea marcada por su predecesor, el presidente Clinton, declaró que su país establecería una asociación global con India y que la ayudaría a convertirse en una potencia mundial en el siglo XXI (Chadda, 2015, p. 161).

El acuerdo nuclear fue suscrito durante la visita de Bush, pero recién pudo ser aprobado en el Parlamento indio en octubre 2008, luego de superar una serie de objeciones. La Cámara de Comercio Norteamericana estimó que el acuerdo produciría cien mil millones de dólares en contratos a empresas de su país (Chadda, 2015, p. 162). En lo político, Washington avanzó hacia convertirse en un socio de confianza para la India en busca de ganar un aliado de primer nivel en Asia que pudiera servir de contrapeso al ascenso de China.

La India, por su parte, cosecha los beneficios de su acercamiento con EE.UU. sin que este hecho limite su política exterior. Desde 1998, como hemos anotado, ha venido mejorando las relaciones con Rusia y China; además, ha formado el foro de los BRICS (el cual incluye también a Brasil y Sudáfrica), que persigue aumentar el peso de estos países en la economía mundial.

Recientemente, la India, bajo el gobierno del BJP, ha dado dos pasos importantes que traen a la mente su política de No Alineamiento y fortalecen su posición en el mundo en desarrollo. Ha sido cofundadora en 2014 de un Banco de Desarrollo de los BRICS con un fondo de cien mil millones de dólares, que da una nueva dosis de poder a este grupo en el sur. Y se perfila como un nuevo miembro de la Organización de Cooperación de Shanghai, fundada por Rusia y China con un 
enfoque primordial en el Asia Central aunque para muchos un naciente contrapeso de la OTAN ${ }^{24}$.

Por otro lado, el gobierno de Modi continúa la inserción de la India en el movimiento de integración en el Asia, centrado en la ASEAN, consolida la presencia del país en el África, e intenta diversificar las relaciones económicas con América Latina (que ya son importantes con Brasil), aprestándose a iniciar la negociación de un TLC con el Perú.

\section{Conclusiones}

En poco más de medio siglo de existencia, la India se transformó en un Estado poderoso e influyente, conducida fundamentalmente por el liderazgo de Nehru e Indira Gandhi. Este liderazgo, guiado por un propósito sostenido, consiguió modificar las estructuras de la sociedad. Para ello contó con el apoyo del Partido del Congreso y de una burocracia estatal, heredada de la época colonial.

Por un largo período se mantuvo una imagen externa de un país pobre y atrasado que subestimaba los avances del modelo de desarrollo indio, el cual combinó una fuerte intervención económica del Estado con la democracia liberal. Por esta misma subestimación hoy se destaca únicamente el impacto de las reformas de los años 1990 para la transformación de la India.

En realidad, el país comenzó tempranamente a formar mano de obra técnica de primera calidad, se convirtió en una potencia industrial a mediados de la década de 1960 y logró la autosuficiencia alimentaria en la de 1970. La tasa de crecimiento desde 1950 hasta el momento de las reformas económicas (1991) había sido de 4\% y en verdad comenzó a elevarse desde 1975.

En sus relaciones exteriores, la India consiguió una posición prominente de autonomía y prestigio bajo el No Alineamiento de Nehru. Bajo Indira se consolidó como potencia regional (1971) y culminó una primera fase de su ascenso como potencia nuclear (1974).

Con el fin de la Guerra Fría, la caída de la URSS contribuyó en distinta medida al cambio del modelo de crecimiento, que la convirtió en potencia económica, y a una reorientación de la política exterior que mejoró sus relaciones con la única superpotencia restante.

24 La OCS aprobó en su cumbre de 2014 los procedimientos para admitir nuevos miembros. Entre los candidatos
se hallan India y Pakistán, así como Irán y Afganistán 
En tanto que la construcción y el posicionamiento externo del Estado indio han tenido un notable progreso, la formación de su identidad como nación ha registrado menos éxitos. Nehru quiso edificar un Estado laico que permitiera a los diversos elementos culturales de la India encontrar por si solos la unidad, pero en la década de 1980 adquirió gran fuerza política una corriente que busca crear una nación hindú. Desde fines de la década de 1990, esta fuerza lidera coaliciones que se alternan en el gobierno con coaliciones del Partido del Congreso.

La prueba de una bomba atómica en 1998, por el gobierno nacionalista del BJP, fue un punto de inflexión en el ascenso de la India. Tras un período de sanciones, las oportunidades que ofrecían su economía y la conveniencia de una eventual alianza frente a China llevaron a Washington a una negociación política del tema y a un arreglo bilateral (2005-2008).

Después del acuerdo nuclear con EE.UU., India aparece hoy como la sexta potencia nuclear y la tercera economía del mundo. Se proyecta que su economía superaría en unos años a la china, impulsada por el bono demográfico y por su especialización en tecnologías de información.

¿Puede hablarse de India como una gran potencia en el corto o mediano plazo?

Subsisten problemas estructurales como la corrupción, una infraestructura todavía insuficiente y un porcentaje significativo de pobreza rural y urbana. Pero dos décadas y media después de su parcial apertura al mundo, la India ha demostrado la viabilidad y beneficios de este nuevo modelo.

Lo que ha cambiado decisivamente en el siglo XXI es que ya no es India la que «toca fuertemente la puerta» al círculo de las grandes potencias, sino que la potencia hegemónica así como varias potencias económicas la eligen para asociarse con ella, anticipando las eventualidades que puedan darse en relación con la evolución del gigante chino. Se trata de una estrategia de ayuda en el ascenso que históricamente ha sido eficaz en el sistema internacional.

Delhi, por su parte, consecuente con su tradición de No Alineamiento, despliega también una estrategia de enriquecimiento de sus vinculaciones con China, Rusia y los BRICS que la impulsan en su escalamiento.

En lo interno, a partir de las tendencias del nacionalismo hindú y del comportamiento del actual régimen del BJP, pensamos en un escenario poco previsto que pudiera darse en los próximos años: que las fuerzas políticas llevaran a avanzar el proceso de construcción nacional hacia la forma de un estado-nación hindú, sin menoscabo de la dinámica modernizadora pero sí de la democracia y la paz social. 


\section{Bibliografía}

Bose, S. y A. Jalal (2014). Modern South Asia. Nueva Delhi: Oxford University Press.

Buzan, B y O. Waever (2003). Regions and Powers: The Structure of International Security. Cambridge: Cambridge University Press.

Chadda, M. (2015). Why India Matters. Nueva Delhi: Viva Books.

Central Intelligence Agency (2015). World Factbook 2014-15. Washington, D.C.: NTIS.

Chakrabarty, M. (ed.) (2015). Post Nehruvian Politics in India. Calcuta: Levant Books.

Chakraborty, B. (2016). Indian Foreign Policy: Philosophical, Theoretical and Strategic Outlines. En B. Chakraborty y D. Nandy (eds.), An Outline of Indian Foreign Policy and Relations. Calcuta: Mitram.

Das, D. (2015). India; from Curzon to Nehru and after. Nueva Delhi: Rupa.

Dhume, S. (2016). Narendra Modi is losing India's free market liberals. Wall Street Journal, 31, January.

Diro, D. (2010). After Empire: The Birth of a Multipolar World. Nueva York: Nation Books.

Dodd, C. (1972). Political Development. Londres: Macmillan.

Flavoni, F.D. (2003). Historia de la India. Madrid: A. Machado.

Griffin, K. (1999). Alternative Strategies for Economic Development. Houndmills: Palgrave. http://dx.doi.org/10.1057/9780230599918

Guha, R. (2007). India after Gandhi; The History of the World's Largest Democracy. Nueva Delhi: Picador.

Hardgrave, R. y S. Kochanek (1993). India; Government and Politics in a Developing Nation. Fort Worth: Harcourt, Brace, Jovanovich.

Little, I.M.D. (1982). Economic Development; Theory, Policy and International Relations. Nueva York: Basic Books.

Malhotra, I. (1989). Indira Gandhi: A personal and political biography. Londres: Hodder \& Stoughton.

McLeod, J. (2002). The History of India. Westport: Greenwood Press.

Ortiz, E. (2010). India entre las grandes reformas y la actualidad. Diplomacia, 122, enero-mazo.

Purcelli, G. (2008). El extraño ascenso de la India. Res Diplomática, 3, junio.

Rachman, G. (2011). Zero-Sum Future in an Age of Anxiety. Nueva York: Simon and Schuster.

Renouvin, P. y J.-B. Duroselle (1967). Introduction to the History of International Relations. Nueva York: Praeger.

Rose, L. (1976). The foreign Policy of India. En J.N. Rosenau, K.W. Thompson y G. Boyd, World Politics. Nueva York: The Free Press.

Rosser, J. y M. Rosser (2004). Comparative Economics in a Transforming World Economy. Nueva Delhi: Prentice-Hall of India.

Rustow, D. (1967). A World of Nations. Washington. D.C.: The Brookings Institution

Rothermund, D. (2008). India; The Rise of an Asian Giant. New Haven: Yale University Press. 
Sanyal, S. (2008). The Indian Renaissance: India's Rise After a Thousand Years of Decline. Nueva Delhi: Penguin. http://dx.doi.org/10.1142/9789812818782

United Nations Development Program (2015). Human Development Report 2015. Nueva York: ONU.

Wolpert, S. (1997). A New History of India. $5^{\text {th }}$ ed. Nueva York: Oxford University Press.

World Bank (2015). World Development Indicators. Washington, D.C: World Bank.

Fecha de recepción: 7 de marzo de 2016 Fecha de aprobación: 29 de abril de 2016 